\title{
COMPOSTOS NITROGENADOS EM PLANTAS JOVENS DE MAMOEIRO SOB DEFICIÊNCIA HIDRICA
}

\author{
Karollyne Renata Souza Silva ${ }^{1}$, Tamires Borges de Oliveira ${ }^{2}$, Ellen Gleyce da Silva \\ Lima $^{3}$, Glauco André dos Santos Nogueira ${ }^{3}$, Cândido Ferreira de Oliveira Neto ${ }^{4}$ \\ 1Estudante de Agronomia da Universidade Federal Rural da Amazônia (karollyne- \\ silva@hotmail.com) Belém-Brasil \\ 2Estudante de Mestrado da Universidade Federal Rural da Amazônia \\ 3Estudante de Doutorado da Universidade Federal Rural da Amazônia \\ 4Professor Adjunto Dr. da Universidade Federal Rural da Amazônia
}

Recebido em: 08/09/2015 - Aprovado em: 14/11/2015 - Publicado em: 01/12/2015 DOI: http://dx.doi.org/10.18677/Enciclopedia_Biosfera_2015_117

\begin{abstract}
RESUMO
No Brasil, a fruticultura é uma das principais atividades socioeconômicas da agricultura, e dentro desta importante atividade agrícola, o cultivo do mamoeiro tem-se destacado de maneira significativa, o que permite que o mamão seja uma das frutas mais consumidas no país. O objetivo deste trabalho foi verificar 0 metabolismo do nitrogênio em plantas de mamoeiro submetidas à deficiência hídrica. O experimento foi conduzido em casa de vegetação na Universidade Federal Rural da Amazônia, campus de Capitão Poço, Pa. Foi realizado em delineamento experimental inteiramente casualizado (DIC), com dois tratamentos [irrigado (controle) e deficiência hídrica], com 14 repetições, totalizando 28 unidades experimentais, no qual cada unidade experimental foi composta de duas (2) planta/vaso. As avaliações dos tratamentos foram feitas aos 20 dias da imposição da deficiência hídrica no qual cada unidade foi composta de uma planta/vaso. Os efeitos provocados pela deficiência hídrica causaram uma redução significativa no conteúdo relativo de água, nos teores de nitrato, nos teores da atividade da enzima redutase do nitrato, na glutamina sintetase, nos teores de proteínas e nos pigmentos fotossintetizantes, do contrário, houve um acréscimo nos teores de amônio, teores de aminoácidos e nos teores de amido. Os resultados obtidos durante os 20 dias de deficiência hídrica em plantas de mamoeiro, indicam que essa planta pode ser adaptada a esta condição hídrica.
\end{abstract}

PALAVRAS-CHAVE: aspectos ecofisiológicos, Carica papaya L., respostas bioquímicas.

\section{NITROGENOUS COMPOUNDS IN PAPAYA YOUNG PLANTS UNDER WATER DEFICIT}

\begin{abstract}
In Brazil, the fruticulture is one of the main socio-economic activities of agriculture, and within this important agricultural activity, the papaya cultivation has excelled significantly, allowing papaya is one of the most consumed fruits in the country. The objective of this study was to determine the nitrogen metabolism in papaya
\end{abstract}


plants subjected to water deficit. The experiment was conducted in a greenhouse at the Federal Rural University of Amazônia, Capitão-Poço campus, Pa. It was conducted in a completely randomized design (CRD) with two treatments [irrigated (control) and water deficiency], with 14 repetitions, totaling 28 experimental units , where each experimental unit was composed of two (2) plant / pot. The effects of the water shortage, caused a significant reduction in the relative water content in nitrate levels, the levels of activity of the reductase enzyme nitrate in glutamine synthetase, in protein and photosynthetic pigments, otherwise, there was an increase in ammonium levels, amino acid content and starch content. The obtained results during the 20 days of water deficit in papaya plants, shows that this plant can be adapted to this water condition.

KEYWORDS: ecophysiological aspects, Carica papaya L., biochemical responses

\section{INTRODUÇÃO}

No Brasil, a fruticultura é uma das principais atividades socioeconômicas da agricultura, e dentro desta importante atividade agrícola, o cultivo do mamoeiro temse destacado de maneira significativa, o que permite que o mamão seja uma das frutas mais consumidas no país. As exportações brasileiras de mamão cresceram 17,9\% em 2014 (IBRAF, 2014). As vendas da fruta para o mercado externo totalizaram 33.688 toneladas ante as 28.561 toneladas no ano anterior. A receita gerada neste ano foi de US $\$ 47.058 .855$ superior $12,5 \%$ comparada a 2013 , de acordo com dados do Ministério do Desenvolvimento, Indústria e Comércio Exterior. O estado brasileiro que tem a maior produtividade é o Espírito Santo, com cerca de $80 \mathrm{t} \mathrm{ha}^{-1}$ (AGRIANUAL, 2011).

Mais do que qualquer outro estresse ambiental, a deficiência hídrica dos solos constitui sério problema mundial (CARLIN et al., 2009). Onde a água participa como reagente em numerosas reações metabólicas, sua carência afeta todos os aspectos do crescimento e desenvolvimento dos vegetais (PEREIRA et al., 2012).

O déficit hídrico pode reduzir a produtividade do mamoeiro em até $22 \%$ (POSSE, 2008) e modificar características fisiológicas dos vegetais, tais como conteúdo relativo de água, ajustamento osmótico, variações nos potenciais de água na folha e trocas gasosas com o ambiente. Como relatado nos trabalhos publicados por CAMPOSTRINI et al., (2010), as características de crescimento e desenvolvimento, e a fotossíntese do mamoeiro são significativamente alteradas pela ação de fatores do ambiente, a água no solo e no ar, o vento e o impedimento mecânico do solo.

Com a diminuição do conteúdo relativo de água nas plantas ocorre a promoção de deformações na parede celular, ruptura e/ou quebra das membranas dos cloroplastos, mitocôndrias e organelas, havendo a redução da atividade das reações associadas às membranas (PIMENTEL, 2005). A redutase do nitrato pode ser utilizada como parâmetro indicativo aos estresses ambientais segundo (OLIVEIRA et al., 2005). Além disso, estudos comprovam que os solutos orgânicos protegem as plantas dos estresses através de diferentes mecanismos, incluindo ajustamento osmótico, remoção das espécies ativas de oxigênio, "proteção da integridade das membranas celulares" e "estabilização de proteínas e enzimas" (POMPELLI, 2010; TURKAN, 2011).

Neste contexto, medidas da atividade fotossintética são muito utilizadas

para investigar danos causados no aparato fotossintético, pois fornecem ENCICLOPÉDIA BIOSFERA, Centro Científico Conhecer - Goiânia, v.11 n.22; p. 7722015 
informações gerais sobre o estado fisiológico da planta. Trabalhos que envolvem estresse de temperatura (CAMARGO, 2010) e déficit hídrico (GONÇALVES et al., 2010) têm mostrado que as plantas respondem a tais mudanças por meio de alterações no cloroplasto e no aparelho fotossintético, o que afeta as propriedades fotossintéticas e, consequentemente, o acúmulo de biomassa.

Com isso, os estudos dos efeitos de estresse abióticos no desenvolvimento dos vegetais servem como subsídios para pesquisas agrícolas e florestais, além de tornarem-se potenciais indicadores dos mecanismos de tolerância das plantas às condições adversas. Diante do exposto, objetivou-se verificar o metabolismo do nitrogênio em mudas de mamoeiro submetidas à deficiência hídrica.

\section{Local do experimento}

\section{MATERIAL E MÉTODOS}

O trabalho foi realizado em Casa de Vegetação da Universidade Federal Rural da Amazônia (UFRA), no campus de Capitão Poço, localizado na microrregião do Guamá no Estado do Pará, com latitude de 01941"3 6' S, longitude 04706"39' W e cerca de 73 m de altitude média da área.

\section{Amostragem}

O delineamento experimental utilizado foi o inteiramente casualizado, no qual as mudas foram submetidas a dois regimes hídricos: irrigado (controle) e deficiência hídrica, sendo esta última simulada por meio da suspensão da irrigação no período de 20 dias, as plantas controle foram irrigadas diariamente em média de $250 \mathrm{~mL}$ de água para compensar as perdas por evapotranspiração. Cada regime hídrico possuía 14 repetições, totalizando 28 unidades experimentais, no qual cada unidade experimental foi composta de duas plantas/vaso.

As avaliações dos tratamentos foram realizadas com 20 dias da imposição da deficiência hídrica, tempo este determinado em experimento preliminar, cujo tempo foi necessário para promover uma deficiência hídrica moderada/severa.

Os vasos foram dispostos no espaçamento de 0,30 m entre linhas e 0,30 m entre plantas, apresentando $0,30 \mathrm{~m}$ de altura por $0,30 \mathrm{~m}$ de diâmetro, com capacidade para $7,5 \mathrm{Kg}$ de substrato, cada vaso foi preenchido utilizando $7 \mathrm{Kg}$ da mistura de 3:1 (v:v), sendo três partes de terra preta, caracterizada com Latossolo Amarelo e uma de esterco de galinha.

Foi aplicada a análise de variância nos resultados e comparadas às médias pelo teste de Tukey ao nível de $5 \%$ de significância, realizadas através do SASINSTITUTE (2008).

\section{Coleta das plantas e variáveis fisiológicas e bioquímicas}

Foram feitas duas coletas destrutivas, sempre por volta das 9:00 horas, no qual as plantas foram separadas em raiz, caule, folhas. As amostras de cada parte foram reservadas para a determinação da porcentagem de umidade através da determinação da massa seca em estufa de circulação forçada de ar a $70^{\circ} \mathrm{C}\left(+/-5^{\circ} \mathrm{C}\right)$ por $72 \mathrm{~h}$. Após a coleta o material seco foi levado para um moinho para preparo de pó fino, armazenados em frascos hermeticamente fechados, colocados em um dessecador e feitas as análises bioquímicas no laboratório de Estudos da Biodiversidade em Plantas Superiores (EBPS). 


\section{DETERMINAÇÕES DAS VARIÁVEIS BIOQUÍMICAS}

\section{Conteúdo Relativo de Água (CRA)}

Analisou-se nas folhas o conteúdo relativo de água, o qual foi obtido utilizando o método descrito por SLAVICK (1979), sendo retirados 30 discos foliares $(10 \mathrm{~mm}$ de diâmetro) de cada planta, ao acaso, determinando imediatamente a massa dos mesmos (MF1) em balança analítica. Os discos pesados foram transferidos para uma placa de Petri contendo $35 \mathrm{ml}$ de água destilada e deixados na bancada ( $25{ }^{\circ} \mathrm{C}$ ) por um período de 6-7 horas. Após, os discos foram colocados em papel de filtro para retirar o excesso de água (1 $\mathrm{min})$ e, em seguida, pesados para determinar a massa túrgida (MF2). Depois, os discos foram colocados em saco de papel, levados à estufa $\left(75^{\circ} \mathrm{C}\right)$ por $48 \mathrm{~h}$ e, posteriormente, foi de terminada a massa seca dos discos (MS).

\section{Determinação das concentrações de nitrato}

Foram pesados $50 \mathrm{mg}$ das folhas previamente liofilizadas, e adicionadas em tubos de ensaio contendo $5,0 \mathrm{~mL}$ de água destilada, e estes incubados em banhomaria por 30 minutos a $100^{\circ} \mathrm{C}$. Em seguida, este quantitativo foi centrifugado a 3.000 rpm por 10 minutos e retirado o sobrenadante. A reação foi preparada em tubo de ensaio contendo $100 \mu \mathrm{L}$ do extrato $+200 \mu \mathrm{L}$ de solução de ácido salicílico $5 \%(\mathrm{p} / \mathrm{v})$, em ácido sulfúrico concentrado. Após vigorosa agitação em agitador do tipo vortex, adicionaram-se lentamente $4700 \mu \mathrm{L}$ de $\mathrm{NaOH} 2 \mathrm{~N}$. Em seguida, os tubos foram deixados em repouso até atingirem a temperatura ambiente por cerca de 20 minutos. Após este processo, foram feitas leituras em espectrofotômetro na absorbância de $410 \mathrm{~nm}$. O branco foi feito usando no ensaio água deionizada em substituição ao extrato. A concentração de nitrato foi obtida a partir de uma curva padrão com concentrações crescentes de $\mathrm{NO}_{3}^{-}\left(0,0,5,1,0,2,0,3,0,4,0\right.$ e $\left.5,0 \mu \mathrm{mol} \mathrm{mL}^{-1}\right)$. Os resultados foram expressos em mmol de $\mathrm{NO}_{3}{ }^{-} \mathrm{kg}^{-1} \mathrm{MS}$ de tecido. O método utilizado foi o de (CATALDO et al., 1975).

\section{Determinação da atividade da redutase do nitrato}

Foram retirados e pesados aproximadamente $200 \mathrm{mg}$ de discos de $0,5 \mathrm{~cm}$ de diâmetro das folhas. Logo após as amostras foram colocadas em tubos de ensaio, contendo $5 \mathrm{~mL}$ do tampão fosfato $0,1 \mathrm{M}, \mathrm{pH} 7,5$; contendo isopropanol $1 \%(\mathrm{v} / \mathrm{v})$, $\mathrm{KNO}_{3} \mathrm{mM}$ ) e estes cobertos com papel alumínio (tratamento escuro). Em seguida, os tubos foram evacuados com o auxílio de uma bomba de vácuo, durante 2 minutos. Por seguinte, os tubos foram colocados em "banho-maria" a $30 \stackrel{\circ}{ } \mathrm{C}$, por 30 minutos, na ausência de luz. Em tubos de ensaio tipo pirex, foram adicionados alíquotas de $1 \mathrm{~mL}$ de tampão fosfato $+2 \mathrm{~mL}$ do extrato diluído $+1,0 \mathrm{~mL}$ de sulfanilamida $1 \%+1,0 \mathrm{~mL}$ de $\mathrm{N}-1$-naftiletilenodiamina dicloridrato (NNEDA) $0,02 \%$, totalizando um volume final de $5 \mathrm{~mL}$. Em seguida, os tubos foram deixados em repouso por 15 minutos. A leitura foi no espectrofotômetro à $540 \mathrm{~nm}$ contra o branco (3,0 mL de tampão fosfato $+1,0 \mathrm{~mL}$ de sulfanilamida $1 \%+1,0 \mathrm{~mL}$ de NNEDA, 0,02 $\%)$. O resultado da atividade da redutase do nitrato foi estimado através da produção de $\mathrm{NO}_{2}^{-}$no meio de reação, sendo expressa em $\mu$ moles de $\mathrm{NO}_{2}^{-} \cdot \mathrm{g} \cdot \mathrm{MF}^{-1} \cdot \mathrm{h}^{-1}$, a partir de uma curva-padrão obtida com $\mathrm{KNO}_{2}$ p.a (Sigma). O método empregado foi o método in vivo preconizado por HAGEMAN \& HUCKLESBY (1971). 


\section{Concentrações de amônio livre}

Foram pesados $50 \mathrm{mg}$ de massa seca (MS) das folhas em pó, e colocados em tubos de ensaio de $15 \mathrm{~mL}$, adicionando-se $5 \mathrm{~mL}$ de água destilada e levados ao banho-maria por $30 \mathrm{~min}$ a $100^{\circ} \mathrm{C}$. Após a extração as amostras foram centrifugadas em centrífuga de bancada a 1000 rpm e os sobrenadantes coletados para obtenção do extrato total. Nos tubos de ensaio foram acrescentados $400 \mu \mathrm{L}$ de extrato total + $2,5 \mathrm{~mL}$ da solução A (5 g de fenol + 0,025 g de nitroprussiato de sódio/ $500 \mathrm{~mL}$ de água destilada) e homogeneizado em vortex, acrescentando $2,5 \mathrm{~mL}$ da solução $B$ (2,5 g de $\mathrm{NaOH}+12,6 \mathrm{~mL}$ de hipoclorito de sódio/ $500 \mathrm{~mL}$ de água destilada) e foram agitados novamente em vortex, levando-os ao banho-maria por $20 \mathrm{~min}$ a $37^{\circ} \mathrm{C}$. Após esse período foram removidos do "banho-maria" e deixados em repouso por $40 \mathrm{~min}$, em seguida, levados para fazer a leitura no espectrofotômetro a $625 \mathrm{~nm}$ e usando-se água destilada (em substituição ao extrato) + reagentes como branco. As concentrações de amônio livre foram estimadas a partir da curva-padrão construída com $\left(\mathrm{NH}_{4}\right)_{2} \mathrm{SO}_{4}$ p.a (Sigma). Os resultados foram expressos em mmol de $\mathrm{NH}_{4}{ }^{+} / \mathrm{kg}$ de MS. Para isso utilizou-se o método descrito por (WEATHERBURN, 1967).

\section{Determinação da Atividade da glutamina sintetase}

Adicionou-se $0,2 \mathrm{~g}$ de massa seca das raízes e das folhas em pó em $5 \mathrm{~mL}$ $(2 \mathrm{~mL}+2 \mathrm{~mL}+1 \mathrm{~mL} / 2$ minutos cada) de tampão de extração TRIS-HCl $25 \mathrm{mM}, \mathrm{pH}$ 7,6, contendo: $10 \mathrm{mM}$ de $\mathrm{MgCl}_{2} .6 \mathrm{H}_{2} \mathrm{O}+10 \mathrm{mM}$ de $\beta$-2-mercaptoetanol + PVP $5 \%$ $(\mathrm{p} / \mathrm{v})+5 \mathrm{mM}$ de EDTA-Na. Depois de trituradas, foram filtradas em pano fino de seda e centrifugadas a $30.000 \mathrm{~g}(21.000 \mathrm{rpm})$, em centrífuga refrigerada à $0^{\circ}-4^{\circ} \mathrm{C}$, por 30 minutos. O sobrenadante foi congelado para posterior análise. A reação foi preparada em tubo de ensaio, com $600 \mu \mathrm{L}$ de tampão de reação TRIS-HCl $0,25 \mathrm{M}$, $\mathrm{pH} 7+200 \mu \mathrm{L}$ de glutamato de sódio $0,3 \mathrm{M}, \mathrm{pH} 7+200 \mu \mathrm{L}$ de ATP $30 \mathrm{mM}, \mathrm{pH} 7+$ $200 \mu \mathrm{L}$ de $\mathrm{Mg} \mathrm{SO}_{4} .7 \mathrm{H}_{2} \mathrm{O} 0,5 \mathrm{M}+500 \mu \mathrm{L}$ de extrato de folhas $+200 \mu \mathrm{L}$ de solução de hidroxilamina $\left(\mathrm{NH}_{2} \mathrm{OH} 1,0 \mathrm{M}+\mathrm{NaOH} 1,0 \mathrm{M}\right.$ na proporção 1:1). Foi misturado rigorosamente, em vortex e incubado em banho-maria à $30^{\circ} \mathrm{C}$, por 30 minutos. Em seguida, removeu-se os tubos do banho-maria e adicionou-se $500 \mu \mathrm{L}$ de solução férrica $\left[\mathrm{FeCl}_{3} .6 \mathrm{H}_{2} \mathrm{O} 10 \%(\mathrm{p} / \mathrm{v})\right.$ em HCl 0,2 $\mathrm{M}$ + ácido tricloroacético (TCA.) $24 \%$ $(\mathrm{p} / \mathrm{v})+\mathrm{HCl} 50 \%(\mathrm{v} / \mathrm{v})$ na proporção 1:1:1 ] e centrifugado em centrífuga de mesa a $7.000 \mathrm{~g}$, durante 10 minutos. A leitura foi feita em espectrofotômetro a $540 \mathrm{~nm}$, usando-se água destiladas + reagentes (exceto solução de hidroxilamina) como branco. A atividade da glutamina sintetase (GS) foi determinada a partir da curva padrão de $\gamma$-glutamil-hidroximato e os resultados foram expressos mmoles de $\gamma^{-}$ glutamil-hidroximato / $\mathrm{kg}$ MS de tecido/hora. A atividade da glutamina sintetase foi determinada pelo método "in vitro" segundo (KAMACHI et al., 1991).

\section{Concentrações de aminoácidos solúveis totais}

Foram pesados $50 \mathrm{mg}$ das folhas e das raízes, e colocados em tubos de ensaio com $5 \mathrm{~mL}$ de água deionizada, fechados hermeticamente e incubados em banho-maria a $1000^{\circ}$, durante 30 minutos. Em seguida, os tubos foram centrifugados a $6.000 \times \mathrm{g}$, por 10 minutos. Após a extração o sobrenadante foi coletado e desenvolvido a reação para dosagem dos aminoácidos. Alíquotas de 0,1 $\mathrm{mL}$ do extrato foram colocadas em tubos de ensaio e acrescidas de 0,4 $\mathrm{mL}$ de água mille-Q. Em seguida $0,250 \mathrm{~mL}$ de uma solução tamponada, $\mathrm{pH} 5,0$, contendo 0.2 mol. $L^{-1}$ de citrato; $0,250 \mathrm{~mL}$ do reagente de ninhidrina (KCN 0,1 mmol. $\mathrm{L}^{-1}$ e ninhidrina 
$5 \%$ em methoxy etanol) foi adicionado. Após misturar bem em vortex os tubos foram hermeticamente fechados e colocados em "banho-maria", no qual permaneceram pelo tempo de 15 minutos à temperatura de $100^{\circ} \mathrm{C}$. E m seguida, a reação foi interrompida em banho de gelo, momento em que foram adicionados $1,5 \mathrm{~mL}$ de uma solução de etanol $50 \%$ (v/v). Após os tubos permanecerem por 20 minutos em temperatura ambiente e em seguida, efetivadas leituras em espectrofotômetro, a 570 $\mathrm{nm}$, sendo os teores de aminoácidos livres totais, determinado com base em uma curva padrão ajustada a partir de concentrações crescentes de uma mistura padronizada de L - glutamina. A concentração de aminoácidos livres totais foi determinada segundo método descrito por PEOPLES et al., (1989).

\section{Determinação das concentrações de proteínas solúveis totais}

Foram colocados em tubos de ensaio de $15 \mathrm{~mL} 100 \mathrm{mg}$ de pó da matéria seca das raízes e das folhas em 5,0 mL do tampão de extração (Tris- $\mathrm{HCl} 25 \mathrm{mM} \mathrm{pH}$ 7,6). Em seguida os tubos, devidamente lacrados, ficaram sobre o processo de agitação durante 2 horas no "shacker". Após esse processo, os tubos foram centrifugados em centrífuga de bancada (2000 rpm por 10 minutos). Em seguida, foram colocados nos tubos de ensaios $100 \mu \mathrm{L}$ do sobrenadante após a centrifugação $+2,5 \mathrm{~mL}$ do reagente de Bradford. Após este processo os tubos manualmente foram agitados delicadamente (para não desnaturar as proteínas). Com 15 min de repouso as leituras foram realizadas no espectrofotômetro a $595 \mathrm{~nm}$, contra o branco que encerra $100 \mu \mathrm{L}$ de água $+2,5 \mathrm{~mL}$ do reagente de Bradford. As concentrações de proteínas solúveis totais foram estimadas a partir da curva-padrão construída com soro albumina bovina p.a (Sigma). Os resultados foram expressos em $\mathrm{mg}$ proteína/ $\mathrm{g}$ MS. As concentrações de proteínas solúveis totais foram determinadas segundo o método de BRADFORD (1976).

\section{Determinação do teor de clorofilas $a, b$ e totais}

A determinação dos pigmentos fotossintéticos foi realizada com $25 \mathrm{mg}$ de tecido foliar, sendo as amostras homogeneizadas no escuro e na presença de $2 \mathrm{ml}$ de acetona a $80 \%$ (Nuclear). Subsequentemente foi centrifugado a $5.000 \mathrm{~g}$ por minuto a uma temperatura de $5^{\circ} \mathrm{C}$, em que o sobrenada nte foi removido e a quantificação das clorofilas $a, b$, carotenóides e total utilizando espectrofotômetro Femto (700S), de acordo com a metodologia de LICHTHENTHALER (1987).

\section{RESULTADOS E DISCUSSÃO}

\section{Conteúdo Relativo de Água}

A suspensão da irrigação ao longo dos 20 dias do experimento promoveu uma redução considerável no conteúdo relativo de água (CRA) das plantas mantidas sob deficiência hídrica (Figura 1) chegando a valores próximos de 58\%. Enquanto as plantas irrigadas obtiveram valores de $79 \%$ ao longo do experimento.

A redução do conteúdo relativo de água nas plantas sob deficiência hídrica ocorreu devido à menor disponibilidade de água no solo, interferindo na formação de um gradiente de concentração e desfavorecendo a absorção de água pela planta. $O$ decréscimo na disponibilidade de água no solo ocasiona queda no potencial hídrico nas folhas das plantas, afetando as trocas de dióxido de carbono e o metabolismo da planta (REIS et al., 2008; ALVES et al., 2012; SILVA et al., 2013). 
Resultados semelhantes foram encontrados por WANG, (2014) em folhas de mudas de seringueira clone GT1, onde houve uma diminuição continua com a gravidade do estresse submetido.

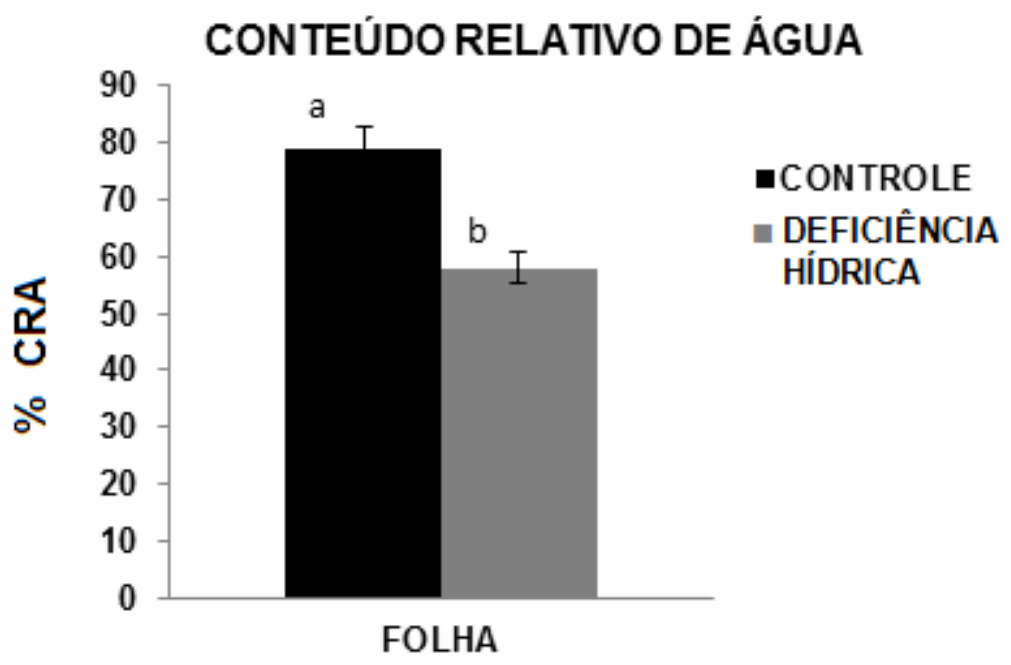

FIGURA 1. Conteúdo relativo de água em plantas jovens de mamoeiro mantidas durante 20 dias sob suspensão hídrica. As letras a e b mostram diferença estatística entre os tratamentos, comparadas pelo teste de Tukey ao nível de $5 \%$ de probabilidade. As barras representam os desvios padrões das médias.

\section{CONCENTRAÇÃO DE NITRATO}

Foi verificado que as concentrações de nitrato diferiram estatisticamente entre os tratamentos controle e deficiência hídrica, tanto na raiz quanto na folha (Figura 2). As concentrações apresentaram uma redução significativa em $89 \%$ nos tecidos foliares de mamoeiro submetidas à deficiência hídrica com $0,04 \mu$ moles de $\mathrm{NO}_{3}{ }^{-}$ /gMS em relação ao tratamento controle 0,37 $\mu$ moles de $\mathrm{NO}_{3}{ }^{-} / \mathrm{gMS}$. Nas raízes, os níveis de nitrato também apresentaram um decréscimo significativo de $82 \%$ quando submetidas à deficiência hídrica $\left(0,11 \mu\right.$ moles de $\left.\mathrm{NO}_{3}{ }^{-} / \mathrm{gMS}\right)$ em comparação com tratamento controle $\left(0,61 \mu\right.$ moles de $\left.\mathrm{NO}_{3}{ }^{-} / \mathrm{gMS}\right)$.

Está diminuição nas plantas submetidas a deficiência hídrica, ocorreu devido à diminuição do CRA, onde o nitrato $\left(\mathrm{NO}_{3}{ }^{-}\right)$é a principal forma de nitrogênio absorvido do solo pelas plantas, sendo o amônio na forma $\mathrm{NH}_{4}{ }^{+}$a substancia que auxilia nesse processo. Segundo MATIMATI et al., (2014), o nitrogênio pode regular a transpiração e o fluxo de massa dos nutrientes, onde o $\mathrm{NO}_{3}{ }^{-}$modula a condutância hidráulica das raízes, através do controle das aquaporinas e o óxido nítrico foliar modula a condutância estomática, juntamente com a regulação dos efeitos do $\mathrm{pH}$ e fitormônios. Esses resultados apresentam consonância com OLIVEIRA et al., (2011) quando trabalhando com a espécie gabiroba, observaram reduções nos teores de nitrato nas plantas submetidas a deficiência hídrica. 


\section{CONCENTRAÇÖES DE NITRATO}

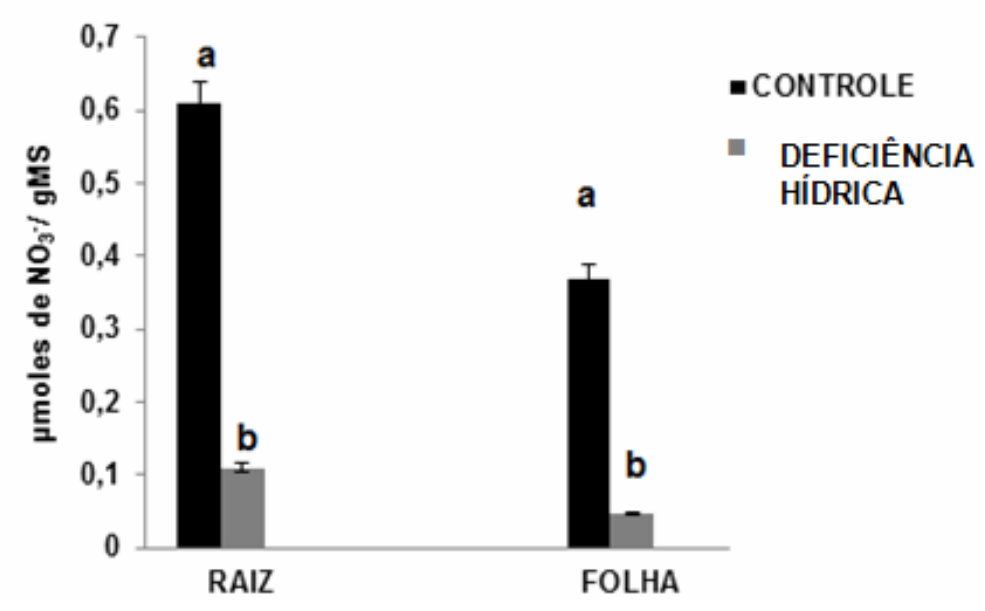

FIGURA 2. Concentrações de nitrato em raízes e folhas de plantas jovens de mamoeiro mantidas durante 20 dias sob suspensão hídrica. As letras a e b mostram diferença estatística entre os tratamentos, comparadas pelo teste de Tukey ao nível de $5 \%$ de probabilidade. As barras representam os desvios padrões das médias.

\section{ATIVIDADE DA REDUTASE DO NITRATO}

A atividade da Redutase do Nitrato em 20 dias de experimento foi afetada nos tratamentos submetidos à deficiência hídrica, onde os resultados tiveram uma redução de 3,4 e $\square 10,66$ vezes, respectivamente folha e raiz comparadas ao tratamento com irrigação de $0,17 \square \mu$ moles $\square \mathrm{NO}_{2}{ }^{-} / \mathrm{g} \quad \mathrm{MF} / \mathrm{h}$ e $\square$ nas raízes $\square 0,32 \square$ umoles $\square \mathrm{NO}_{2}{ }^{-} / \mathrm{g} \mathrm{MF} / \mathrm{h}$.

Essa redução está relacionada ao baixo fluxo de água na corrente transpiratória, diminuindo a atividade dessa enzima nas plantas sob deficiência hídrica, trazendo como possível consequência à diminuição da transpiração e com isso também o fluxo de nitrato para as folhas uma vez que essa enzima é altamente dependente de seu substrato (HORCHANI et al., 2010). Resultados semelhantes foram constatados por MELO et al., (2014) ao trabalharem com mudas de Coffea arabica cultivar Siriema obtiveram declínios na atividade da enzima redutase do nitrato em 12 dias. 


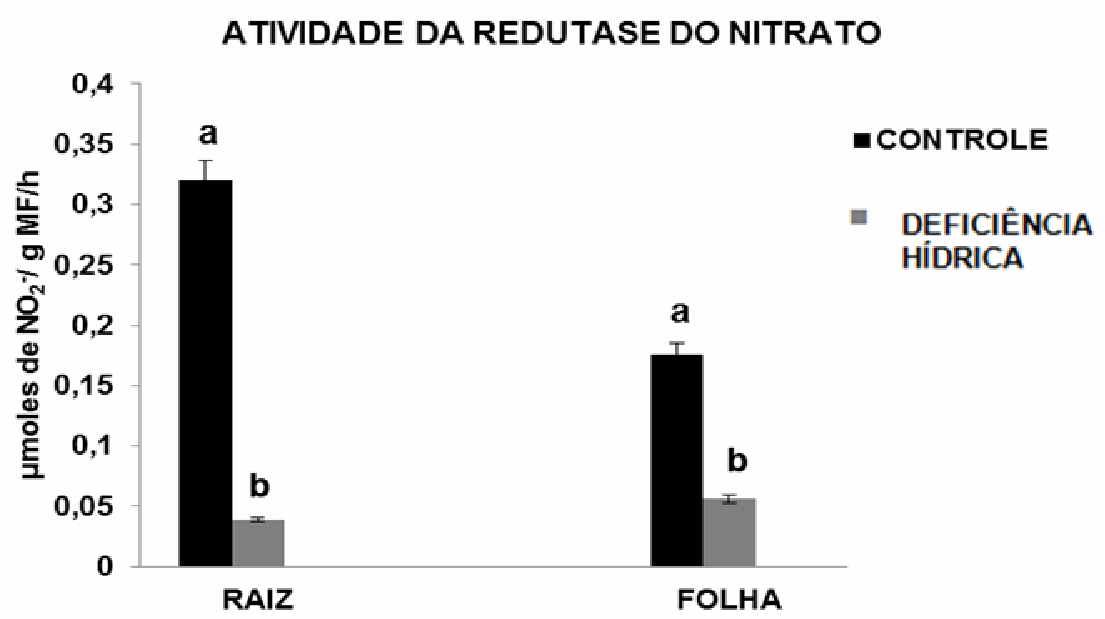

FIGURA 3. Atividade da redutase do nitrato em raízes e folhas de plantas jovens de mamoeiro mantidas durante 20 dias sob suspensão hídrica. As letras a e b mostram diferença estatística entre os tratamentos, comparadas pelo teste de Tukey ao nível de $5 \%$ de probabilidade. As barras representam os desvios padrões das médias.

\section{CONCENTRAÇÕES DE AMÔNIO}

As concentrações de amônio livre (Figura 4) apresentaram um acréscimo significante de $37 \%$ nos tecidos foliares das plantas submetidas à deficiência hídrica $\left(9,24 \mathrm{mmol} \mathrm{NH}_{4}{ }^{+} / \mathrm{Kg} \mathrm{MS}\right)$, quando comparadas ao tratamento controle em que os teores encontrados foram de $5,83 \mathrm{mmol} \mathrm{NH}_{4}^{+} / \mathrm{Kg} \mathrm{MS}$. Nas raízes, níveis de amônio livre também apresentaram concentrações elevadas no tratamento submetido a deficiência hídrica $\left(17,82 \mathrm{mmol} \mathrm{NH}_{4}{ }^{+} / \mathrm{Kg} \mathrm{MS}\right)$ quando comparados ao tratamento sob disposição hídrica com $10,11 \mathrm{mmol} \mathrm{NH}_{4}{ }^{+} / \mathrm{Kg} \mathrm{MS}$.

Este aumento nas concentrações de amônio pode estar ligado a rota do glutamato desidrogenase (GDH), que atua na dependência de NADH, desaminando o glutamato gerando amônio $\left(\mathrm{NH}_{4}{ }^{+}\right)$e o 2-Oxiglutarato para formação do mesmo, promovendo um acúmulo de amônio através de um descompasso entre sua produção e a redução da atividade da enzima glutamina sintetase (Figura 5) (CRUZ et al., 2008). Resultados semelhantes foram encontrados por CASTRO et al., (2007) trabalhando com plantas de Tectona grandis L. f. submetida a deficiência hídrica. 


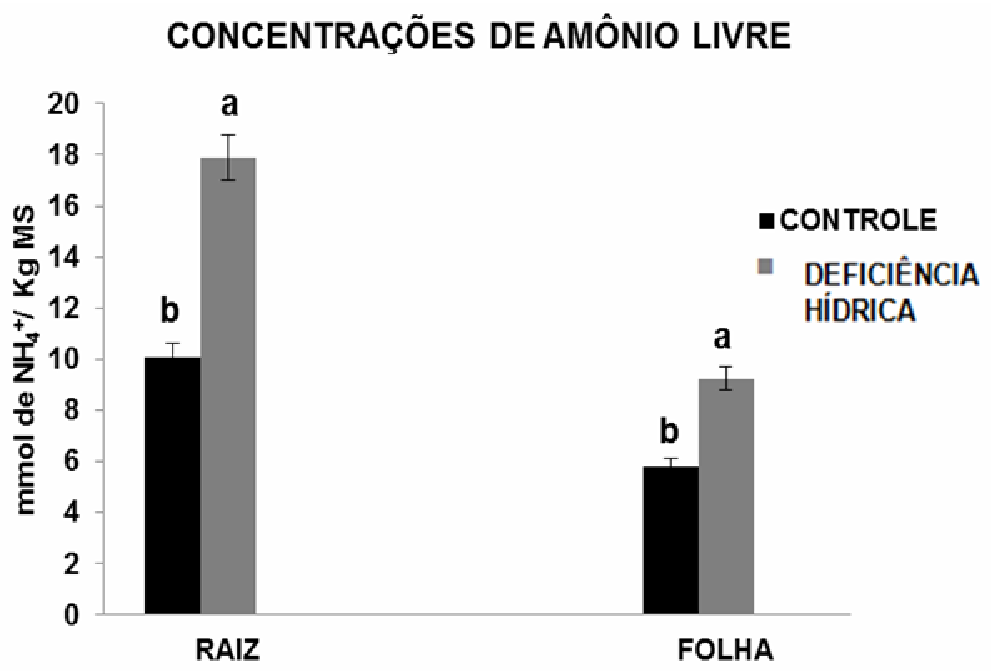

FIGURA 4. Concentrações de amônio livre em raízes e folhas de plantas jovens de mamoeiro mantidas durante 20 dias sob suspensão hídrica. As letras a e b mostram diferença estatística entre os tratamentos, comparadas pelo teste de Tukey ao nível de $5 \%$ de probabilidade. As barras representam os desvios padrões das médias.

\section{ATIVIDADE DA GLUTAMINA SINTETASE}

A atividade da glutamina sintetase (Figura 5) nas folhas apresentou 17,02 e $4,21 \mathrm{mmoles} \mathrm{GGH} / \mathrm{Kg}$ MS nos tratamentos submetidos ao controle e deficiência hídrica, respectivamente. Nas raízes essa atividade mostrou médias de 12,01 mmoles GGH/Kg MS para o controle hídrico e 5,94 mmoles $\mathrm{GGH} / \mathrm{Kg}$ MS quando submetido à deficiência hídrica (Figura 5).

Esses resultados evidenciam que quando submetidos à deficiência hídrica, a enzima torna-se menos efetiva devido às baixas concentrações de ATPs no meio celular, reduzindo o açúcar disponível para a produção de energia e de poderes redutores haja vista esta enzima é dependente de energia oriunda da atividade fotossintética nas folhas e do processo respiratório nas raízes (SWARBRECK et al., 2011; TERCÉ-LAFORGUE et. al., 2013).

Em trabalhos desenvolvidos por CARNEIRO, (2014) com plantas de seringueira durante 21 dias mostrou que a atividade da enzima glutamina sintetase foi bem maior nas folhas de plantas mantidas sob capacidade de campo. 


\section{ATIVIDADE DA GLUTAMINA SINTETASE}

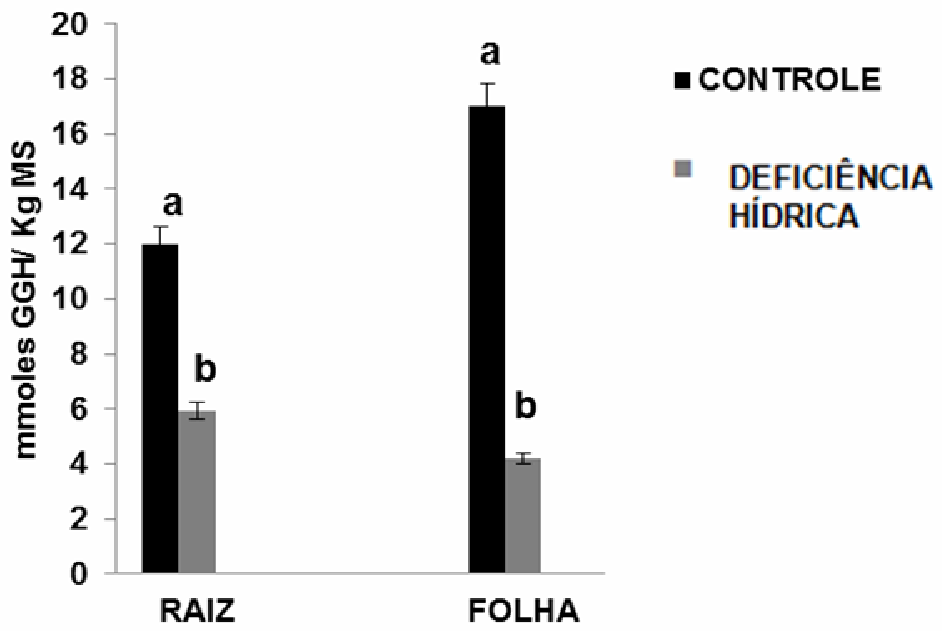

FIGURA 5. Atividade da glutamina sintetase em raízes e folhas de plantas jovens de mamoeiro submetidas durante 20 dias sob suspensão hídrica. As letras a e b mostram diferença estatística entre os tratamentos, comparadas pelo teste de Tukey ao nível de $5 \%$ de probabilidade. As barras representam os desvios padrões das médias.

\section{AMINOÁCIDOS E PROTEINAS SOLÚVEIS TOTAIS}

As concentrações de aminoácidos solúveis totais aumentaram expressivamente nos tratamentos submetidos à deficiência hídrica, apresentando médias dos valores de 44,2 e $28,1 \mu \mathrm{mol}$ de AA/g MS nas folhas e raízes, respectivamente. Esses resultados proporcionaram diferenças estatísticas quando comparado as plantas controle (Figura 6A). Os teores de proteína diminuíram significativamente quando as plantas foram submetidas à deficiência hídrica (Figura 6B), apresentando os valores de 2,41 mg de Proteínas/g MS nas plantas controle e $1,12 \square \mathrm{mg}$ de Proteínas/g MS nas plantas submetidas a deficiência hídrica. Na raiz foram observadas concentrações de 1,62 e $0,45 \square \mathrm{mg}$ de Proteínas/g MS, nas plantas sob controle e deficiência hídrica, respectivamente.

Para MARAGHNI et al., (2011) o metabolismo das proteínas é sensivelmente afetado pela deficiência hídrica, contudo o processo de biossíntese de proteína e um dos primeiros eventos metabólicos paralisados após a percepção do estresse, com isso dá-se início a proteólise, evento que promove um aumento no conteúdo de aminoácidos solúveis, com consequente diminuição da concentração de proteínas (BRITO et al., 2008).

Resultados apresentados por OLIVEIRA et al., (2013), com mudas de graviola submetidos a deficiência hídrica por um período de 40 dias apresentaram resultados semelhantes com o atual trabalho para as concentrações de aminoácidos e proteínas tanto nas folhas como nas raízes. 
CONCENTRAÇOES DEAMINOÁCIDOS LIVRES TOTAIS

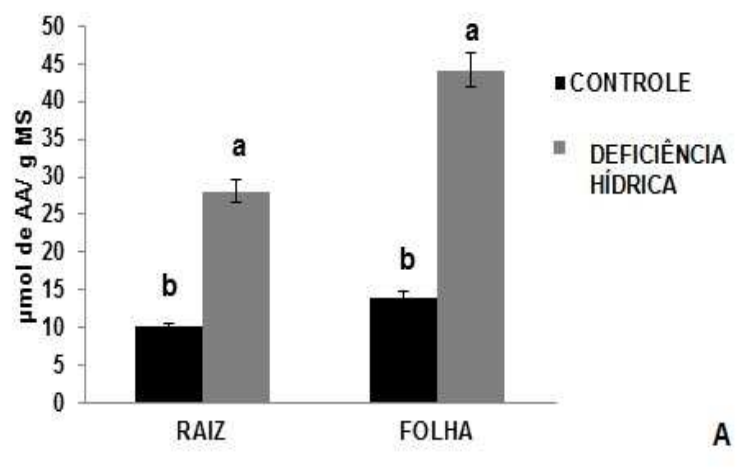

CONCENTRAÇÖES DE PROTEINAS SOLÚVEIS TOTAIS

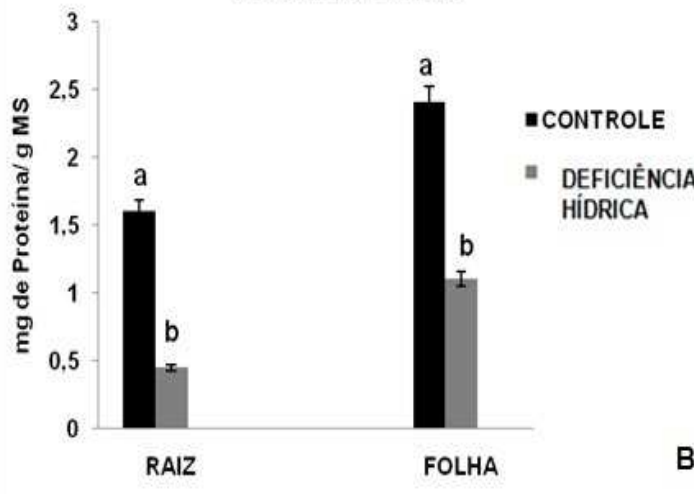

FIGURA 6. Concentrações Aminoácidos Livres Totais (A) e Proteínas Solúveis Totais (B) em raízes e folhas de plantas jovens de mamoeiro submetidas durante 20 dias sob suspensão hídrica. As letras a e b mostram diferença estatística entre os tratamentos, comparadas pelo teste de Tukey ao nível de $5 \%$ de probabilidade. As barras representam os desvios padrões das médias.

\section{PIGMENTOS FOTOSSINTETICOS}

Os teores de clorofila a foram observados 1,76 e $0,87 \mathrm{mmol} \mathrm{Kg}^{-1} \mathrm{MF}$ nos tratamentos controle e deficiência hídrica, respectivamente (Figura 7). Na clorofila $b$ foram observados nas plantas controle e deficiência hídrica as concentrações de 1,59 e $0,52 \mathrm{mmol} \mathrm{Kg}^{-1} \mathrm{MF}$, respectivamente. Nos teores de clorofila total foram obtidos 3,01 e 1,38 mmol Kg${ }^{-1}$ MF nos tratamentos controle e deficiência hídrica, respectivamente (Figura 7). Em relação aos carotenóides foram observados nas plantas controle e deficiência hídrica as concentrações de 1,97 e $1,84 \mathrm{mmol} \mathrm{Kg}^{-1}$ MF, respectivamente.

Os resultados revelam que ocorreu uma diminuição significativa na quantidade de todos os pigmentos fotossintéticos após a seca, e isto provavelmente implicará em menor absorção de energia luminosa e também menores taxas de fotossíntese, que culminarão em menor desempenho da planta. A fluorescência da clorofila a é usada no monitoramento do processo fotossintético, para se obter informações sobre a inibição, danos na transferência de elétrons no fotossistema II (FSII) (ZHAO et al., 2011) ou para detectar perturbações no sistema fotossintético (BACKER, 2004). Corroborando com os resultados, GONÇALVES et al., (2010), trabalhando com variedades de cana-de-açúcar RB92579 e RB98710, encontraram valores de 0,76 e 0,78 , respectivamente. 


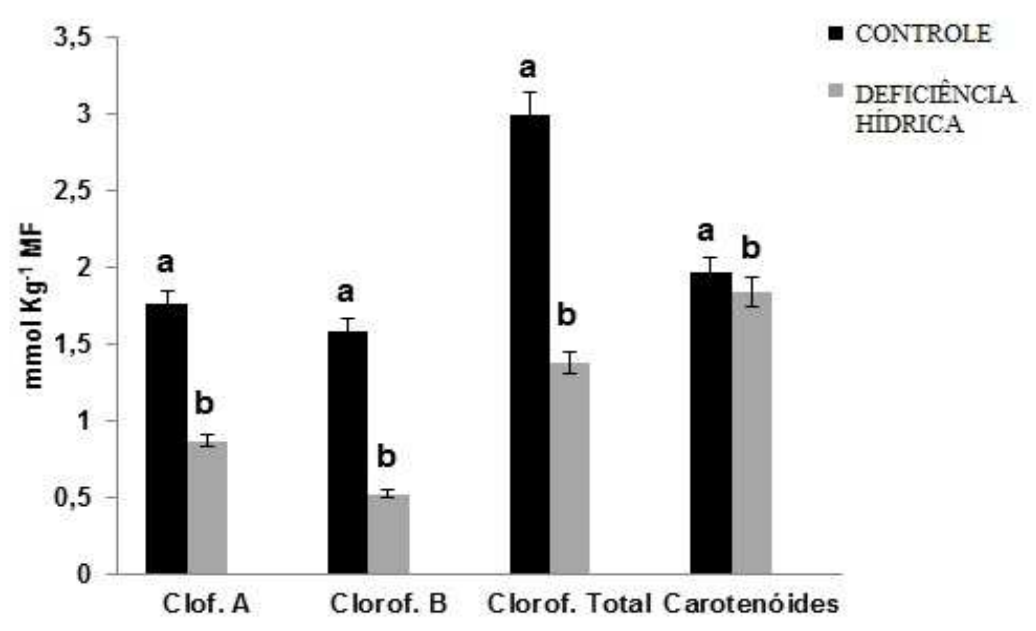

FIGURA 7. Teores de clorofila $a, b$, total $(a+b)$ e carotenóides em folhas de plantas jovens de mamoeiro submetidas durante 20 dias sob suspensão hídrica. As letras a e b mostram diferença estatística entre os tratamentos, comparadas pelo teste de Tukey ao nível de $5 \%$ de probabilidade. As barras representam os desvios padrões das médias.

\section{CONCLUSÕES}

O déficit hídrico de 20 dias em plantas de mamoeiro promoveu queda no conteúdo relativo de água e nos pigmentos fotossintéticos nas folhas, concentrações de nitrato e nas atividades da redutase do nitrato e glutamina sintetase, reduzindo também os teores de proteínas nas partes avaliadas.

O baixo conteúdo de água provocou acréscimos nas concentrações de aminoácidos e amônio livre tanto nas raízes quanto nas folhas, indicando que essa planta pode ser adaptada à deficiência hídrica.

\section{REFERÊNCIAS}

AGRIANUAL. Anuário da Agricultura Brasileira: Mamão. São Paulo: FNP, consultoria e Agroinformativos, p. 325-332. 2011.

ALVES, G. A. R.; SANTOS, F. B. G. dos.; LOBATO A. K. da S.; YUEN TAN D. K; OLIVEIRA NETO, C. F. de; COSTA, R. C. L. da, ÁVILA, F. W.; MARQUES, D. J; GALATE, R. S. dos. Water relations, nitrogen compounds and enzyme activities in leaf and root of young Yellow Lapacho (Tabebuia serratifolia) plants subjected to flooding. Plant Omics Journal, v. 5, n. 3, p. 216-222, 2012.

BACKER, N. R., ROSENQVIST, E. Applications of chlorophyll fluorescence can improve crop production strategies: Na examination of future possibilities. Journal of Experimental Botany, v. 55, ํ‥ 403, p. 1607-1621, 2004. 
BRADFORD, M.M. A rapid and sensitive method for the quantitation of microgram quantities of protein utilizing the principle of protein-dye binding. Analitic Biochemistry. 722: 248-254. 1976.

BRITO, L.K.F.L. et al. Alterações no perfil de frações nitrogenadas em calosde canadeaçúcar induzidas por deficit hídrico. Pesquisa Agropecuária Brasileira, Brasília, v.43, n.6, p.683-690, 2008.

CAMARGO, M. B. P. The impact of climatic variability and climate change on Coffea arabica L. in Brazil. Bragantia, v.69, n.1, p.239-247, 2010.

CARLIN, S. D.; SANTOS, D. M. M. dos. Indicadores fisiológicos da interação entre déficit hídrico e acidez do solo em cana-de-açúcar. Pesquisa agropecuária Brasileira, Brasília, v.44, n.9, p.1106-1113, set. 2009.

CARNEIRO, M.M.L.C. Fisiologia de plantas jovens de seringueira cultivadas em diferentes fontes nitrogenadas e sob baixa disponibilidade de água e oxigênio. 108 f. Tese (doutorado) - Universidade Federal de Lavras, Lavras, MG. 2014.

CASTRO, D. S.; LOBATO, A. K. S. ; MENDES, F. S. ; OLIVEIRA NETO, C. F. ; CUNHA, R. L. M. ; COSTA, R. C. L. Atividade da Redutase do Nitrato em Folhas de Teca (Tectona grandis L. f.) sob Déficit Hídrico. Revista Brasileira de Biociências, 2, p. 936-938, jul. 2007.

CATALDO, D. A.; HAROON, M.; SCHRADER, L. E. \& YOUGS, V. L. Rapid Colorimetric determination of nitrate in plant tissue by nitration of salicylic acid. Commum Soil Science and Plant Analysis 6(1): 71-80. 1975.

CRUZ, J. L.; PELACANI, C. R.; ARAÚJO, W. L. Efeito do nitrato e amônio sobre o crescimento e eficiência de utilização do nitrogênio em mandioca. Ciência Rural, Santa Maria, v.38, n.3, p.643-649, mai-jun, 2008.

GONÇALVES, E. R.; FERREIRA, V. M.; SILVA, J. V.; ENDRES, L.; BARBOSA, T. P.; DUARTE, W. G. Trocas gasosas e fluorescência da clorofila a em 33 variedades de cana-de-açúcar submetidas à deficiência hídrica. Revista Brasileira de Engenharia Agrícola Ambiental, v.14, n.4, p.378-386, 2010.

HAGEMAN, R. H. \& HUCKLESBY, D. P. Nitrate reductase from righer plants. In: Methods in Enzymology, 17 A: 491-503. 1971.

HORCHANI, F., S. ASCHI-SMITI AND R. BROUQUISSE. Involvement of nitrate reduction in the tolerance of tomato (Solanum lycopersicumL.) plants to prolonged root hypoxia. Acta Physiology Plant., 32: 1113-1123. 2010.

IBRAF. Associação Brasileira dos Produtores e Exportadores de Papaya Brapex. Disponível em <http://blogdoibraf.blogspot.com.br/2015/01/exportacoes-demamao-crescem-179-em-2014.html> Acesso em: 31 mar. 2015 
KAMACHI, K.; YAMAYA, T.; MAE,T.; OJIMA, K. A. Role for glutamine synthetase in remobilization of leaf nitrogen during natural senescence in rice leaves. Plant Physiology. 96, 411-417, 1991.

LICHTHENTHALER, H.K. Chlorophylls and carotenoids: pigments of photosynthetic biomembranes. In: Colowick SP, Kaplan (ed) Methods in Enzimology, v.148. Academic Press, San Diego. p.350-382. 1987.

MARAGHNI M.; GORAI M.; NEFFATI M. The Influence of Water-Deficit Stress on Growth, Water Relations and Solute Accumulation in Wild Jujube (Ziziphus lotus).Journal of Ornamental and Horticultural Plants, 1(2): 63-72 p., 2011.

MATIMATI, I.; VERBOOM, G. A.; CRAMER, M. D. Nitrogen regulation of tranpiration controls mass-flow acquisition of nutrientes. Journal of Experimental Botany, Oxford, v. 65, n. 1, p. 159-168, nov. 2014.

MELO, E. F.; , C. F. ; BRUM. C. N. F. ; PEREIRA, F. J. ; CASTRO, E. M. ; CHALFUN JÚNIOR, A. . Anatomic and physiological modifications in seedlings of Coffea arabica cultivar siriema under drought conditions. Revista Ciênc. Agrotec., Lavras, v. 38, n. 1, p.25-33, 2014.

OLIVEIRA, L. J. da; SILVA, S. M. da; COSTA NETTO, A. P.; SILVA, S. M.da; SILVA, F. M. de S. M. da. Características agronômicas e atividade da redutase do nitrato em plantas de Campomanesia sp. sob estresse hídrico. Revista Agrarian, Dourados, v.4, n.11, p.43-53, 2011.

OLIVEIRA, L. M.; SILVA, J. N.; COELHO, C. C. R; NEVES, M. G.; SILVA R. T. L.; OLIVEIRA NETO, C. F. Pigmentos fotossintetizantes, aminoácidos e proteínas em plantas jovens de graviola submetida ao déficit hídrico. Agroecossistemas, v. 5, n. 1, p. 39-44, 2013.

OLIVEIRA, M. A. J.; BOVI, M. L. A.; MACHADO, E. C.; RODRIGUES, J. D. Atividade da redutase de nitrato em mudas de pupunheira (Bactris gasipaes). Ciência Rural, Santa Maria, v. 35, n. 3, p. 515-522, 2005.

PEOPLES, M. B.; FAIZAH, A. W.; REAKASEM, B. E.; HERRIDGE, D. F. Methods for evaluating nitrogen fixation by nodulated legumes in the field. Australian Centre for International Agricultural Research Canberra. p. 76. 1989.

PEREIRA, J. W. de L; MELO FILHO, P. de A; ALBUQUERQUE, M. B; NOGUEIRA, R J. M. C; SANTOS, R.C. Mudanças bioquímicas em genótipos de amendoim submetidos a déficit hídrico moderado. Revista Ciência Agronômica, v. 43, n. 4, p. 766-773, out-dez, 2012.

PIMENTEL, C. Respostas fisiológicas à falta d' água: Limitação difusiva ou metabólica? Estresses ambientais: Danos e benefícios as plantas- MXM Gráfica e editora. Recife: UFRP, Imprensa universitária, 500p. 2005. 
POMPELLI, M.F., BARATA-LUÍS, R., VITORINO, H.S., GONÇALVES, E.R., ROLIM, E.V., SANTOS, M.G., ALMEIDA-CORTEZ, J.S., FERREIRA, V.M., LEMOS, E.E., ENDRES, L. Photosynthesis, photoprotection and antioxidant activity of purging nut under drought deficit and recovery. Biomass and Bioenergy v.34, 1207-1215. 2010.

POSSE, R. P.; SALASSIER, B.; SOUZA, E. F.; PEREIRA, M. G.; MONNERAT, P. H.; GOTTARDO, R. D.; Relação entre a produtividade do mamoeiro e o déficit hídrico (ky) na região Norte Fluminense, Revista Brasileira de Engenharia Agrícola e Ambiental. v.13, n.2, p.158-164, 2009.

REIS, F. O.; CAMPOSTRINI, E. Trocas gasosas e eficiência fotoquímica potencial em mamoeiro do grupo 'Formosa' cultivado em condição de campo. Bragantia, v.67, n.4, p. $815-822,2008$.

SILVA, M. A. ; SANTOS, C.M. ; Arantes, M.T. ; BRUNELLI, M.C. ; HOLANDA, L.A. . Respostas fisiológicas de cultivares de cana-de-açúcar submetidas à deficiência hídrica e à reidratação . Revista Caatinga (Online), v. 26, p. 28-35, 2013.

SLAVICK, B. Methods of studying plant water relations. New York, Springer Verlang. p. 449. 1979.

Statistical Analysis System - SAS . SAS/STAT® 9.2 User's Guide. Version 9.2. Cary, NC: SAS Institute Inc. 584 p. 2008.

SWARBRECK, S. M.; DEFOIN-PLATEL, M.; HINDLE, M.; SAQI, M.;. HABASH, D. Z. New perspectives on glutamine synthetase in grasses. Journal of Experimental Botany. 62, n. 4, 1511-1522. 2011.

TERCÉ-LAFORGUE, T; BEDU， M.; DARGEL-GRAFIN， C.; DUBOIS F.; GIBON Y.; RESTIVO F.M.; HIREL, B. Resolving the role of plant glutamate dehydrogenase: II. Physiological characterization of plants overexpressing the two enzyme subunits individually or simultaneously. Plant \& Cell Physiology, Kioto, v. 54, n. 10, p. 16351647, Oct. 2013.

TURKAN, I., 2011. Plant Responses to Drought and Salinity Stress: Developments in Post-Genomic Era. In Advances in Botanical Research. Vol. 57. Elsevier .p 593.

WANG, L.F. Physiological and molecular responses to drought stress in rubber tree (Hevea brasiliensis Muell. Arg.) Plant Physiology and Biochemistry, v.83, p.243249, 2014.

WEATHERBURN, M. W. Phenol hipochlorite reaction for determination of ammonia. Analytical Chemistry. V. 39: 971-974. 1967.

ZHAO, D., GLYNN, N. C., GLAZ, B., COMSTOCK, J. C., AND SOOD, S. Orange rust effects on leaf photosynthesis and related characters of sugarcane. Plant Disease, V. 95, no 6 . P. 640-647, 2011. 